\title{
CARACTERES DA EXPERIÊNCIA
}

André Barata

\section{Os Pontos de vista da primeira e terceira pessoas}

Se existe um ponto de partida absolutamente seguro para a Filosofia é este: há experiência. Dizer "Há experiência" não é exibir uma verdade estéril; pelo contrário, é o ponto suficientemente recuado para lançar com alguma fecundidade a discussão acerca da existência de duas formas básicas de experiência com sentido.

Se se fala de estados físicos é porque os experienciamos de alguma maneira e se os qualificamos como físicos é porque os distinguimos de outros estados, ditos mentais. A esta distinção não é raro encontrar associada a ideia de que haja um externalismo que se instancia em diversos planos, aliás nem sempre concordantes - externalismo mental (a respeito das atitudes proposicionais), teórico (a respeito das entidades observacionais), semântico (relativamente à determinação da referência), etc. Independentemente do valor da distinção entre estados mentais e físicos, sobre o qual não nos pronunciaremos, interessa tornar patente o infundado da sua articulação com o externalismo dito semântico, isto é, com a tese de que a referência das nossas expressões não é determinada internamente, mas pelo contrário depende da natureza física das coisas mesmas.

Nestes termos, procuraremos já nesta primeira secção refutar o externalismo semântico, determinando, correctamente, o estatuto metafísico, por assim dizer, dos 'referentes' do nosso discurso. Com esses resultados a respeito do estatuto da referência, poderemos propor um critério pelo qual se possa distinguir entre as perspectivas da primeira e da terceira pessoa.

Com o bem conhecido argumento da Terra Gémea, Hilary Putnam procurou mostrar que representações indiscerníveis - estados mentais idênticos (desde que caracterizados funcionalmente) - podem obter referentes diferentes, i.é, que duas representações mentais, apesar de indiscerníveis de um ponto de vista interno, poderão representar objectos externos distintos (no caso do argumento da terra Gémea, as referências/extensões $\mathrm{H}_{2} \mathrm{O}$ e XYZ) ${ }^{1}$.

I Cf. Putnam, Hilary, 1975. Mind, Language and Reality, "The Meaning of 'meaning", Cambridge University Press, Cambridge, pp. 215-271. 
Ora, se estados mentais funcionalmente idênticos não referem necessariamente o mesmo, torna-se ilegítimo afirmar, em termos fregeanos, que a referência é determinada exclusivamente pelo sentido, ou ainda, que a extensão de um termo é determinada pela sua intensão. Assim, quando Putnam afirma "meanings just ain't in the head!" quer com isso dizer que a referência não é determinada pelo estado mental correspondente. Daqui resulta uma posição externalista no que respeita à determinação da referência de um termo (uma vez que não são os estados mentais que a determinam, mas, de acordo com Putnam, uma cadeia causal histórica - daí a teoria causal da referência)

Semanticamente, as posições externalista e internalista definem-se, pois, a respeito do problema da determinação da referência de um termo. Caso a determinação da referência/extensão de um termo não possa ser atribuída ao estado mental correspondente, como defende Putnam, então estamos perante uma posição externalista. Podemos especificá-la como Externalismo semântico (em contraste com um internalismo semântico) ${ }^{2}$.

Ora, a nossa objecção ao presente argumento de Putnam prende-se com o seu entendimento do que seja a referência, mais particularmente, com o modo pelo qual identifica como referente do termo 'água' na Terra a substância $\mathrm{H}_{2} \mathrm{O}$ e como referente do mesmo termo na Terra Gémea a substância XYZ. Por que razão há-de Putnam adoptar a estrutura molecular como índice da substancialidade do referente? Por que razão deverão ser as propriedades químicas, e não quaisquer outras, as propriedades a ter em conta na identificação do referente do termo 'água' nos dois planetas? ${ }^{3}$ Estas questões só

\footnotetext{
2 Especificando a oposição externalismo/internalismo a respeito das atitudes proposicionais (e já não do ponto de vista semântico) os resultados da experiência de pensamento de Putnam são bem diversos. Com efeito, de acordo com a posição defendida pelo externalismo mental as crenças e restantes atitudes proposicionais de um indivíduo envolvem na sua caracterização o ambiente em que esse indivíduo se situa, ou seja, envolvem as propriedades do mundo e a disposição dos seus objectos. Já os defensores do internalismo mental não só afirmam que não é esse o caso, como não poderia nunca ser esse o caso. Ora, neste sentido, o argumento da Terra Gémea joga evidentemente em favor dos internalistas - uma vez que condições externas diferentes, no plano dos referentes, não determinam conteúdos mentais distintos, então teríamos produzida evidência no sentido de uma outra fonte de determinação dos conteúdos mentais que não é nem pode ser atribuída ao ambiente externo do sujeito desses conteúdos. Podemos especificar esta posição como um internalismo do conteúdo mental (em contraste com um externalismo do conteúdo mental), ou ainda, para seguir a designação do próprio Putnam, realismo interno.

${ }^{3}$ Franck Jackson e David Braddon-Mitchell colocam as mesmas questões, com a particularidade de distinguirem dois níveis de problemas - "The depth problem: why does 'water' pick out a property of something at a certain point, at a certain 'depth', in the causal chain that ends up with our using the word 'water'? The spread problem: why does 'water' pick out from the very many properties of water the property that it does?" (Jackson \& Braddon-Mitchell, 1996. Philosophy of Mind and Cognition, Blackwell, Oxford) E no que toca à teoria causal da referência os mesmos autores pela sua parte adiantam a ideia de que "(...) the reference of natural kind terms depends on a mixture of causal and non-causal factors" (ibidem).
} 
poderiam encontrar resposta sob uma presunção metafísica injustificável pela qual se afirmasse que são essas e não outras as propriedades que efectivamente - i.é, em termos ontológicos - diferenciam uma dada substância de qualquer outra. Não há razão de espécie alguma para considerar que a individuação de um referente esteja dependente daquilo que individualiza um seu suposto correspondente real. Mas, na verdade, o que Putnam pressupõe é justamente este vínculo e, a partir daí, limita-se a imaginar uma situação em que dois sujeitos física e psicologicamente idênticos referir-se-iam a coisas diferentes porque aquilo a que se referem possui de facto uma estrutura molecular diferente. Acontece que o vínculo não só é desnecessário como, a ser admitido, impossibilitaria, em rigor, que alguma vez se individualizasse referentes. Com efeito, se assumo como referente do termo 'água' $\mathrm{H}_{2} \mathrm{O}$ é porque conheço a estrutura molecular da água. Este conhecimento pela minha parte é condição necessária da minha assunção. Mas daqui não se segue que tal conhecimento seja condição necessária, e muito menos suficiente, para que faça uso do termo 'água' e para que tal termo seja referencial. De outra forma, não teria sido possível a um Vasco da Gama referir-se com toda a propriedade à água. Nem sequer se segue que 'água' se refira a algo que tenha necessariamente de ser $\mathrm{H}_{2} \mathrm{O}$. E se o aprofundamento do conhecimento tende a limitar a referência, também não são inéditos os casos em que sucede o inverso (por exemplo, para o mesmo Vasco da Gama o termo 'cisne' referir-se-ia apenas ao que hoje chamamos cisnes brancos quando, na verdade, sabemos que existem também cisnes negros). Dito de outro modo, a individualização de um referente é função do meu conhecimento e não do que supostamente será uma substância de um modo independente do meu conhecimento (seja directo ou indirecto, mais ou menos comunicado, etc.). Todo o argumento de Putnam parte, pois, da eleição de certas propriedades da coisa como se elas não dependessem de um posição de conhecimento, como se fossem de um ordem distinta daquelas que determinaram a referência antes da química molecular; enfim, como se um dado estádio do conhecimento sobre a água, por acaso, ou nem tanto, o de Putnam, correspondesse a um olhar de Deus.

Se o habitante da Terra e o seu análogo na Terra Gémea estão nos mesmos estados psicológicos é porque se referem exactamente à mesma coisa bebível, incolor, imprescindível para a sobrevivência de ambos, de que a sede é desejo de, etc., etc. Se pretendermos encontrar o que determina a referência do termo 'água' para ambos os habitantes tê-lo-emos de fazer nessas propriedades discriminatórias, aqueles que fazem parte do mundo reconhecível de cada um, e não naquilo que desconhecem, precisamente a estrutura molecular que Putnam privilegia. Em suma, não há referentes senão para o sujeito que a eles se refere; por isso, para ambos os seres que empregam o termo 'água' esse termo tem um e não dois referentes. 
O erro de Putnam ao sustentar o externalismo semântico reside, em síntese, em entender os referentes como entidades reais externas pelo que, dessa forma, se torna absurdo supor que estejam nas nossas cabeças ${ }^{4}$. O nosso ponto está, portanto, em afirmar que o externalismo semântico é falso; que, pelo contrário, o que há é um internalismo semântico. Os referentes são determinados logicamente em função do conhecimento e fixados - numa relação que interessaria considerar - por um uso linguístico competente. $\mathrm{O}$ que as coisas são independentemente do conhecimento é uma miragem de profetas; o que elas vão sendo para nós, sob a mediação do nosso conhecimento delas, é o que as determina como referentes das nossas expressões linguísticas e dos nossos estados mentais.

Se os referentes do nosso discurso e, por extensão, de toda a nossa experiência não são do mundo real, então é certo que os estados físicos, tais como nos são acessíveis, são-no primeiramente não como estados do mundo real, mas como estados de um mundo experienciado. Ray Jackendoff, partindo da verificação óbvia de que aquilo que experienciamos está sempre parcialmente determinado por condições inerentes ao sujeito de experiência, adopta a este respeito uma distinção entre mundo real (real world) e mundo projectado (projected world). ${ }^{5}$ Note-se que nada aqui compromete uma posição solipsista, nem sequer uma inacessibilidade completa ao mundo real. Nega-se, simplesmente, que o mundo real seja directamente acessível. O seu acesso não é nem imediato nem directo ${ }^{6}$. Em todo o caso, não é nele que os referentes dos nossos actos expressivos e, por extensão, da nossa experiência residem. O seu âmbito específico é o mundo experienciado/projectado, isto é, o campo - descritível em termos fenomenológicos - de que emergem as objectidades de uma experiência, sejam de ordem perceptual ou não?.

${ }^{4}$ Ray Jackendoff, já em 1983 e no quadro de uma semântica da linguagem natural, punha em causa a atribuição ao mundo real dos referentes da nossa linguagem - "Such tactics, however, totally removes semantics from the domain of psychology; it is not the semanticist's business anymore to ask how people internalise language. (...) I vote for giving up the assumption that reference equals real-world extension." (Jackendoff, 1983. Semantics and Cognition, MIT Press, Massachusetts, p. 93).

5 "If indeed the world as experienced owes so much to mental processes of organization, it is crucial for a psychological theory to distinguish carefully between the source of environmental input and the world as experienced. For convenience, I will call the former the real world and the latter the projected world (experienced world or phenomenal world would also be appropriate)" (Jackendoff, idem, p. 28).

${ }^{6}$ Para a distinção entre carácter imediato e carácter directo da experiência perceptiva cf. Gil, Fernando, 1996, Tratado da Evidência, trad. Maria Bragança, IN-CM, §38, p. 64.

${ }^{7} \mathrm{~A}$ este respeito, é interessante trazer à colação a distinção husserliana entre actos posicionais ou téticos e actos perceptivos, pela qual estes últimos não são senão uma espécie daqueles. Jakendoff é, na sua linguagem, também bastante esclarecedor: "(...) the projected world is much richer than the 'percepts' of traditional psychology: it embraces not only direct perceptual experience, with all this attendant organization, but also a wide variety of abstractions and theoretical constructs"(Jackendoff, idem, p. 29) 
Com estes elementos, evidencia-se a subordinação da distinção entre os estados físicos de um mundo real e os estados mentais à distinção entre os referentes de um mundo projectado e os actos que os expressam. Como esta última distinção se faz no seio da experiência, legitima-se então a diferenciação de dois momentos da experiência provida de sentido - um momento expressivo e um momento referencial.

Mas se os estados do mundo real não correspondem nem directa nem imediatamente aos referentes da experiência, se o que corresponde a estes são os estados de um mundo projectado ou da experiência, então toda a perspectiva que se restrinja à consideração de estados descritíveis externamente - o que designaremos, genericamente, como perspectiva da terceira pessoa - não pode deixar de se reportar às condições da experiência e, em última análise, deve encontrar o seu âmbito específico no seio da própria experiência. Ou seja: não havendo referentes independentes da experiência daí a refutação de um externalismo semântico - dever-se-á falar de referentes enquanto momento abstracto das experiências referenciais.

Por exemplo, uma caracterização funcionalista dos estados mentais através de inputs sensoriais e outputs comportamentais, ou seja através do desempenho causal dos estados mentais, não pode deixar de procurar as suas condições de possibilidade na própria experiência. Por outras palavras, existindo duas perspectivas, habitualmente designadas da primeira e da terceira pessoas, a razão da sua diferenciação deve ser encontrada na própria experiência, mais em particular, nos tipos de experiência que é possível discriminar fenomenologicamente. Ora, a distinção entre um momento expressivo e um momento referencial da experiência, atrás indicada, e a vinculação da perspectiva da terceira pessoa às experiências referenciais, dá-nos um claro sinal no sentido de investigar a possibilidade de dois tipos de experiência um referencial outro não-referencial. Noutros termos: será que o momento não-referencial da experiência pode ser correspondido por experiências não referenciais?

Por outro lado, é relativamente ingénua a presunção de que a perspectiva na terceira pessoa se limita a referentes de actos perceptivos, como se nela não ocorressem outros referentes como correlatos de actos de recordação, imaginação, etc. Se assim fosse, todas as experiências de pensamento (thought experiments) seriam à partida auto-refutantes. Por conseguinte, o que está em jogo na perspectiva da terceira pessoa não é tanto uma limitação aos referentes de actos perceptivos, mas uma limitação a experiências referenciais, isto é, aos actos posicionais em geral.

Por isso, a distinção entre estados físicos e estados mentais não exprime com clareza a distinção entre uma perspectiva na primeira pessoa e uma da terceira pessoa. Aquela distinção é resultante desta e não o inverso. Com efeito, se chego a distinguir entre a água que vejo presentemente e a sua mera recordação, ou mesmo imaginação, em momento ulterior é porque dis- 
ponho de modos distintos de a visar intencionalmente - qualidades de acto intencional distintas para seguir o vocabulário husserliano das Investigações Lógicas $^{8}$. Deste modo, entre a percepção e a recordação, bem como a imaginação (por exemplo da água como uma substância com a composição molecular XYZ), não existe propriamente uma clivagem de perspectivas.

Concluindo, a perspectiva na primeira pessoa não está para a da terceira pessoa como a experiência interior para a exterior (no sentido de out-thereness) porque estas duas últimas podem ser ambas referenciais, isto é, dispor de um referente exterior, mas agora num outro sentido de exterioridade, enquanto não incluído nos elementos reais da vivência. É nesse sentido que Husserl, nas suas Investigações Lógicas, introduz um objecto intencional como correlato de toda a vivência intencional e do qual afirma ser extra mens ${ }^{9}$ e que Frege introduz a célebre distinção entre Sinn e Bedeutung ${ }^{10}$. Tanto a recordação como a percepção da água, atrás exemplificadas, dispõem do mesmo referente - objecto intencional ou referente objectivo para Husserl, Bedeutung para Frege. O que se pretende defender aqui é, pois, que a perspectiva na terceira pessoa corresponde a todas as experiências dotadas de referente (ou, em termos husserlianos, a todos os actos intencionais ${ }^{11}$ ),

80 emprego que faremos daqui em diante da expressão 'qualidade do acto' é pedida de empréstimo a Husserl, conquanto não a vinculemos ao contexto em que é tematizada por Husserl, designadamente enquanto carácter de crença/doxa e suas modalidades. Interessará, para os presentes intentos, apenas a diferenciação entre qualidade do acto e sua matéria, identificando-se esta com a referência objectiva do acto (o objecto visado pelo acto) e aquela com o modo pelo qual o objecto é visado. Daqui, retira-se a observação de que se pode preservar a mesma referência objectiva, fazendo variar o modo como é visada e de que a conversa também se verifica. (Cf. Husserl, E., 1901. Logische Untersuchungen, Investigationes Lógicas, trad. Manuel Morente e José Gaos, 1929, Revista do Occidente, Madrid, V, $\$ 20$ - "A distinção entre a qualidade e a matéria de um acto"). Já em Ideen I, esta distinção é reformulada a partir da tríade de conceitos 'noema', 'núcleo noemático' e 'noesis'. Por outro lado, Husserl desenvolve, a respeito da representação (Vorstellung) a distinção geral entre 'presentação' (Gegenwärtigung) e 'presentificação' (Vergegenwärtigung), sendo a primeira o modo original de dação que caracteriza os actos perceptivos ao passo que a segunda designa um modo de dação por reprodução que pode, por seu turno, ser posicional (que caracteriza a recordação) ou neutralizada (que caracteriza a consciência de imagem esta surge como neutralização de uma presentificação posicional, ou seja, de uma recordação). Os elementos dóxicos, aliás susceptíveis de modificação qualitativa (por exemplo, na consciência de imagem), discriminam a qualidade dóxica que só indirectamente se diz dos actos.

${ }^{9}$ Cf. Husserl, E., 1901. Logische Untersuchungen, I, §12.

10 A expressão Bedeutung à letra traduz-se por significação, mas Frege emprega-a como referência objectiva. Por exemplo, uma expressão sem objecto não tem Bedeutung mas tem Sinn segundo Frege. Husserl, por seu turno, não só critica a Frege este emprego confuso da palavra Bedeutung, como afirma mesmo que as palavras 'significação' (Bedeutung) e 'sentido'(Sinn) são sinónimas. (Cf. Husserl, idem, I, §15)

11 Empregaremos o adjectivo 'intencional' como índice de objectidade de um acto, i.é, como equivalente à presença de um 'objecto (Objeckt) intencional'. Nestes termos, a intenciona- 
seja este real ou imaginário, actualmente presente ou não; sem qualquer compromisso, portanto, com a existência num mundo real (no sentido de Jackendoff) dos referentes. E, em contraste, que a perspectiva na primeira pessoa corresponde a todas as experiências sem referente, mas ainda assim dotadas de sentido (ou, em termos husserlianos, mas em desacordo com Husserl, a todos os actos não intencionais ${ }^{12}$ ). Por outras palavras, a posse ou não de referente é, a nosso ver, o critério suficiente para discriminar se uma dada experiência é tematizável pela perspectiva da terceira pessoa ou não.

\section{Consciência fenomenal e consciência intencional}

Isto que se diz em termos de perspectivas, subentende, como indicámos, uma distinção em termos de experiência. Ned Block fá-lo ao distinguir uma 'consciência fenoménica' (phenomenal consciousness, ou P-consciousness) de uma 'consciência de acesso' (Acess consciousness, ou A-consciousness), sendo que só a segunda acede a uma referência objectiva, representa um objecto, em suma, é consciência de alguma coisa, caracterizando-se portanto pela intencionalidade. Já a P-consciência, segundo Ned Block, deixa-se caracterizar da seguinte maneira:

"P-consciência é experiência. Propriedades P-conscientes são propriedades experienciais. Estados P-conscientes são estados experienciais, i.é, um estado é P-consciente se possui propriedades experienciais. A totalidade das propriedades experienciais de um estado são 'como é que é' tê-lo. Passando dos sinónimos aos exemplos, temos estados P-conscientes quando vemos, ouvi-

lidade é definida em termos mais restritivos do que a mera posse de um sentido ou direccionalidade (aboutness, para empregar uma expressão habitual na literatura mais recente sobre a intencionalidade). Esta acepção corresponde a uma opção terminológica, não envolvendo nenhuma tese sobre o que a intencionalidade seja ou deixe de ser. De qualquer modo, é nestes mesmos termos mais restritivos que Husserl define intencionalidade em Ideen I - "Comme la perception, tout vécu intentionnel a son 'objet intentionnel', c'est-à-dire son sens objectif: c'est même cela qui constitue l'élément fondamental de l'intentionnalité." (Husserl, 1913. Ideen I, Idées directrices pour une phénoménologie, trad. Paul Ricoeur, Gallimard, Paris, 1950, §90, p. 185) Além da implicação de duplo sentido entre intencionalidade e objectidade, entendemos, na esteira da primeira das Investigações Lógicas (cf. I, §12), que as expressões 'objecto intencional' e 'referência objectiva' se equivalem, recusando, pois, a naturalização da referência. Donde que, em suma, intencionalidade, objectidade e referência serão aqui entendidos como termos logicamente intersubstituíveis.

12 Para o Husserl das Investigações, não há actos não intencionais como veremos adiante na secção 5. Tal posição corresponde, a nosso ver, a uma rejeição, avant la lettre, dos qualia. Poder-se-á, porém, encontrar algumas pontes com a temática dos qualia sobretudo em Experiência e Juízo, obra editada por Landgrebe em 1938, e na qual Husserl se coloca num plano pré-objectal, o da passividade originária (Cf. a nota de L. Landgrebe em Husserl, 1938. Expérience et Jugement. Erfahrung und Urteil, trad. Denise Souche-Dagues, P.U.F., Paris, $1991, \S 17$, p. 82, n.1). 
mos, cheiramos, provamos, e temos dores. As propriedades P-conscientes incluem as propriedades experienciais das sensações, sentimentos e percepções, mas também incluiria os pensamentos, os desejos e as emoções. (...) Tomo as propriedades P-conscientes como sendo distintas de qualquer propriedade cognitiva, intencional ou funcional. (Cognitiva $=$ envolvendo essencialmente pensamento; propriedades intencionais $=$ propriedades em virtudes das quais uma representação ou estado é acerca de alguma coisa; propriedades funcionais $=$ e.g., propriedades definíveis em termos de uma programa de computador)."13

Além de Ned Block, também David Chalmers denuncia a confusão entre dois conceitos de consciência que deverão ser separados. Em The Conscious Mind, denomina-os 'consciência fenoménica' (phenomenal consciousness) e 'consciência psicológica' (psychological consciousness), sendo que ao primeiro corresponde uma consciência caracterizada por propriedades fenoménicas, ou seja, "by the way it feels", ao passo que ao segundo corresponde uma consciência caracterizada por propriedades psicológicas, ou seja, "by what it does". Quanto à consciência fenoménica parece não haver qualquer diferença para com a P-consciência de Block; aliás, ambos a designam da mesma maneira. Já quanto à consciência psicológica levantam-se dúvidas, não tanto por Block empregar uma designação diferente, mas sobretudo porque, a um primeiro nível, são caracterizadas de forma tarnbém diferente. Com efeito, enquanto Block fala de propriedades intencionais a propósito da A-consciência, Chalmers fala de propriedades psicológicas a propósito da consciência psicológica ${ }^{14}$. Contudo, a um segundo nível, pode-se verificar que ambos reduzem a propriedades funcionais quer as propriedades intencionais de uma A-consciência quer as propriedades psicológicas de uma consciência psicológica ${ }^{15}$. Assumindo, por um instante, a equivalência entre os conceitos de Block e Chalmers, vale a pena referir ainda que ambos estabelecem a correspondência com as duas perspectivas básicas que começámos por enunciar - "Numa primeira aproximação, os conceitos fenoménicos (phenomenal concepts) lidam com os aspectos na primeira

13 Block, N., 1995. "On a confusion about a Function of Consciousness", in Block, Flanagan e Güzeldere (editores), 1997. The nature of Consciousness, MIT Press, Massachusetts, pp. 381-382.

14 "At the root of all this lie two quite distinct concepts of mind. The first is the phenomenal concept of mind. (...) The second is the psychological concept of mind. This is the concept of mind as the causal or explanatory basis for behavior. According to the psychological concept, it matters little whether a mental state has a conscious quality or not. What matters is the role it plays in a cognitive economy."(Chalmers, D., 1996. The Conscious Mind, Oxford University Press, Oxford, p. 11)

15 "The functionalist account corresponds precisely to the definition I have given of psychological properties. Most nonphenomenal mental properties fall into this class, and can therefore be functionally analysed."(Chalmers, idem, p. 16) 
pessoa da mente (the first-person aspects of mind) e os conceitos psicológicos (psychological concepts) lidam com os aspectos na terceira pessoa."16

Apesar destas correspondências, há para Chalmers um conjunto de 'princípios de coerência' dificilmente aceitáveis, em especial aquele que afirma uma dupla implicação entre consciousness (entendida como o correlato fenoménico da consciência) e awareness (entendida como o seu correlato psicológico). Se é o caso, a nosso ver, que não há awareness sem consciousness (aliás, contra Block ${ }^{17}$ ), já a conversa não é aceitável. Isto porque o paralelismo defendido por Chalmers - e que designa coerência - entre consciousness e awareness, embora não negue tout court a existência de experiências dotadas de sentido mas desprovidas de referente, limita-as ao que designa juízos de segunda-ordem a partir de experiências referenciais. Ora, sucede que esta limitação pode ser exposta facilmente a exemplos que a refutam. Discutir-se-á este ponto adiante, na secção em que se propõe uma caracterização dos qualia (secção 4 'O que os qualia são').

Em todo o caso, defender-se-á aqui a implicação, por parte da awareness (consciência-de, intencional), de uma consciousness (consciência não intencional, fenoménica), seguindo apenas este lado da implicação do princípio da coerência de Chalmers. Mas é ainda de se notar, a este respeito, que um dos aspectos que maior confusão tem sucitado nos esforços por alcançar uma teoria da experiência mais completa tem residido numa insistente tendência a considerar sob a lógica da dualidade o que, na verdade, revela uma relação a três. Michael Martin foca justamente este aspecto em recente ensaio, onde não aceita a simples contraposição entre a teoria dos sense-data e um representacionalismo forte, de carácter conceptual, introduzindo uma noção de representações não-conceptuais ${ }^{18}$, que pode bem ser entendida como representações sem objecto intencional.

16 Chalmers, ibidem.

17 Este defende que, pelo menos conceptualmente, é possível pensar um A-consciência sem P-consciência e vice-versa. (Cf. Block, idem, pp. 385-389)

18 "It is common to reject a simple sense-datum view, and claim instead that one's experience is of a mind-independent world, and that in order for it to be so, one's experience must be representational. This leads some to endorse the view that experience has both representational and non-representational subjective aspects, and for others to embrace purely representational views. Some have questioned whether the representational nature of experience requires that it should be conceptual, and have floated the idea that experience involves a form of non-conceptual representation. But the tendency has been to assume that the choice is between experience as non-representational and subjective, or as involving a mind-independent world and thereby being representational." (Martin, M., 1999. "The Transparency of Experience", http://www.nyu.edu/gsas/dept/philo/courses/concepts/martin.html) 


\section{Caracteres da experiência mental}

Nestes termos, haveria que distingir entre experiências com sentido e referente, por um lado, e experiências sem referente mas nem por isso desprovidas de sentido, por outro. Será de se perguntar se existirão também experiências sem sentido, pergunta a que darei uma resposta positiva a partir da tematização de um certo tipo de experiência visual que denominarei 'ver confuso'. Posto isto podemos discriminar, através da distribuição das possibilidades de ocorrência de sentido e de referência, três tipos de experiência:

1. objectos intencionais/referentes (ou seja: actos dotados de objecto intencional ou referência objectiva) - como os referentes da percepção, a recordação, a imaginação;

2. significações não intencionais ou arreferentes (ou seja: actos dotados de sentido mas sem referente) - como os qualia a respeito da percepção;

3. experiências insignificantes ou, simplesmente, insignificantes - como os sense-data a respeito da percepção.

Note-se que, em rigor, não se trata de três tipos de experiência que concorram entre si; o que estabelece a tipologia é a ocorrência de um, dois ou três caracteres, respectivamente: apenas experiência, experiência com sentido, experiência com sentido e referência. Por outras palavras, o caracter 'experiência' é presente aos três tipos e não difere de uns para os outros. O factor de diferenciação não está, pois, no caracter 'experiência', mas nos dois restantes caracteres que podem acompanhar o primeiro - 'significação' e 'objecto/referência'. ${ }^{19}$

Note-se ainda que pelo facto de os objectos não dependerem da qualidade do acto ${ }^{20}$ - tanto podem ser objectos de um acto perceptivo como de qualquer acto intencional -, os caracteres 'significação' e 'experiência' também não estão de forma alguma vinculados a uma qualidade determinada de acto. Por outras palavras, cada qualidade do acto - seja perceptivo, de memória, imaginativo, etc. - pressupõe a possibilidade destes três tipos de experiência, pois pode ser intencional como não o ser, e pode ser significativo como não o ser. Se se discute as relações entre sense-datum, quale e

19 Observe-se que aqui se fala de experiência em dois sentidos distintos - experiência como acto e experiência como momento do acto. Na segunda acepção a palavra aparece entre aspas e antecedida pela palavra caracter: caracter 'experiência'. O emprego da mesma palavra nos dois casos visa chamar a atenção para o facto de que não há experiência sem o caracter 'experiência', ou seja, que a experiência como acto herda a sua experiencialidade do caracter 'experiência'. Por outro lado, a experiência como acto pode coincidir com o caracter 'experiência' caso nela não se encontrem os restantes caracteres que a podem acompanhar - 'significação' e 'referência'. A afirmação de tal coincidência não se deve, pois, a uma confusão terminológica.

20 A respeito do emprego da expressão 'qualidade do acto', vide supra n. 8 . 
perceptum, outro tanto deve ser feito para a recordação, a fantasia, etc. Donde que seja preferível classificar o sense-datum como um subtipo de experiências insignificantes (caracter único: 'experiência' de qualidade perceptiva), o quale como um subtipo de arreferentes ('significação' + 'experiência' de qualidade perceptiva), o perceptum propriamente dito como um subtipo de objectidade intencional ('objecto intencional/referência' + 'significação' + 'experiência' de qualidade perceptiva).

Esta complicação terminológica pode ser obviada empregando expressões como 'os sense-data e seus pares qualitativos', 'os qualia e seus pares qualitativos', 'os percepta e seus pares qualitativos', entendendo por pares qualitativos o tipo de experiência idêntico para as restantes qualidades de acto. Não obstante o uso que façamos deste artifício, interessa empregar designações genéricas e precisas para os três tipos de experiências. Por isso, propomos falar de insignificantes, arreferentes e referentes.

Parece claro que a perspectiva da terceira pessoa corresponde aos referentes (os objectos visados por actos intencionais). Já a perspectiva da primeira pessoa corresponde aos arreferentes (qualia e seus pares qualitativos $)^{21}$. Sobre os insignificantes, isto é, as sensações e seus pares qualitativos, nenhuma perspectiva é possível pela simples razão de que não possuem qualquer sentido. Neles nada é perspectivado precisamente por neles nada ser reconhecível. E se se estranhar a existência deste tipo de experiência basta recordar todas aquelas situações em que nada se reconhece no que se dá a ver. Refiro-me às situações de ver confuso como a que Wittgenstein expõe nas Investigações Filosóficas:

"Subitamente uma pessoa vê diante de si aparecer uma coisa que não reconhece (pode ser um objecto que lhe seja bastante conhecido, mas numa posição fora do habitual, iluminado de outra maneira); o não-reconhecimento dura talvez alguns segundos."22

21 Sydney Shoemaker emprega, exactamente como Block, a oposição entre propriedades intencionais e propriedades qualitativas (ou fenoménicas), fazendo corresponder as primeiras a objectos intencionais - e por isso mesmo com a propriedade, de segunda ordem, de permanecerem idênticos através de diferentes estados mentais em que sejam visados - e as segundas aos qualia. "If Fred's house looked yellow to him at both $t 1$ and $t 2$, then with respect to colour his house 'looked the same' to him at those two times in the sense that is experiences of it on those two occasions were of the same objective colour, or had the same colour as their 'intentional object'. Call this the intentional sense of 'look the same'. But in another sense his house did not 'look the same' to him at the two times; call this the qualitative sense of that expression."(Shoemaker, S., 1982. "The Inverted Spectrum" in Block, Flanagan e Güzeldere, The Nature of Consciousness, p. 647) Donde que seja razoavelmente pacífico estabelecer dois grupos de conceitos: i) perspectiva da terceira pessoa, A-consciência e objectos intencionais (ou referentes); ii) perspectiva na primeira pessoa, $\mathrm{P}$ -consciência e qualia.

22 Wittgenstein, L., Philosophische Untersuchungen. Investigações Filosóficas, trad. M.S. Lourenço, 1995, Fundação Calouste Gulbenkian, Lisboa, p. 545. 
A experiência por que se passa nesses breves segundos de não reconhecimento - momentos em que se vê algo sem que se percepcione coisa alguma - não é confundível com a experiência dos qualia, pois nessas há uma evidente reconhecimento, ainda que não se trate de um reconhecimento objectal $^{23}$. Note-se ainda que o não-reconhecimento pode não resultar apenas de uma dificuldade de percepção, mas ser induzido por um certo registo de atenção, pelo qual um sujeito permanece atentamente distraído (em vez de distraidamente atento ou, ainda, atentamente atento), i.é, um modo da atenção em que me distraio das coisas para que as coisas não me distraiam, em que evito a tematização do caracter 'significação' ${ }^{24}$

Podemos tentar sistematizar as diferenças atrás apontadas por meio de um quadro:

\begin{tabular}{|l|c|c|c|}
\cline { 2 - 4 } \multicolumn{1}{c|}{} & Experiência & Significação & Referência \\
\hline Estímulo & & & \\
\hline Sense-datum & $\mathrm{X}$ & & \\
\hline Quale & $\mathrm{X}$ & $\mathrm{X}$ & $\mathrm{X}$ \\
\hline Perceptum & $\mathrm{X}$ & $\mathrm{X}$ & \\
\hline
\end{tabular}

(assinalam-se com ' $\mathrm{X}$ ' os caracteres cuja ocorrência se verifica)

23 Já em Metáforas da Consciência dávamos conta deste tipo de experiência, que ilustramos agora com o exemplo de Wittgenstein. "Há experiências sem percepção - é o caso das experiências, aliás não raras, em que sentimos dificuldades em perceber o que estamos em dado momento a ver. Esta dificuldade só é sentida precisamente porque vemos alguma coisa sem que percepcionemos o quê. Esse ver confuso prova a existência de um plano experiencial anterior à percepção e que é condição material desta. Dir-se-ia que estes dois planos tendem a confundir-se tanto mais quanto menos confusa for uma percepção, e que, portanto, há circunstâncias, embora especiais, que nos confrontam com um ver sem percepcionar. A este ver alguma coisa sem percepção de coisa nenhuma chamamos sensação."(Barata, A., 2000. Metáforas da Consciência, Campo das Letras, Porto, p. 202) Observe-se, contudo, que aí a sensação é pensada apenas no âmbito de uma dualidade com a percepção, quando a relação envolve três termos. Por isso, afirmar que 'ao ver alguma coisa sem percepção de coisa alguma chamo sensação' é insuficiente. É preciso explicitar que à sensação falta um referente objectivo, característico da percepção, mas também que lhe falta o caracter sentido, justamente aquele caracter que permite o reconhecimento, desde logo nos qualia.

24 Isto significa que é sempre possível, num certo registo de atenção, converter um quale numa sensação. Veremos adiante que também toda a percepção pode ser convertida num quale. Ou seja: através da focalização da atenção para certos registos, é sempre possível dispensar na experiência de uma representação intencional os caracteres 'significação' e 'objecto' que nela ocorrem. Contudo, note-se, numa experiência em que não ocorram tais caracteres não é possível suscitá-los por nenhuma modificação do modo da atenção. Não se deve confundir este trabalho da atenção que permite a conversão do olhar com a abstracção, numa experiência, de um seu momento. A diferença é que a conversão acede a uma experiência enquanto acto, ao passo que a abstraç̧ão simplesmente isola momentos do acto (cujo acesso resulta apenas de forma derivada). 
Para a discussão que se segue podemos dispensar as sensações e seus pares qualitativos, uma vez que sobre todos estes não é possível nenhuma perspectiva, seja na primeira seja na terceira pessoas. No essencial, a distinção entre as duas perspectivas é uma distinção interna aos tipos de experiência com sentido, ou seja, entre as referenciais e as arreferenciais (ou as intencionais e as não intencionais).

Por outro lado, se a perspectiva da primeira pessoa e a da terceira pessoa (ou, paralelamente, a P-consciência e a A-consciência) são mutuamente irredutíveis tal resulta do facto preciso de a referencialidade importar uma certa exterioridade, cuja natureza está de todo excluída dos qualia e seus pares qualitativos. Não há nenhum termo comum que faça a ponte entre o quale vermelho que vivencio aquando a percepção do lápis vermelho e esse mesmo lápis vermelho que vejo defronte de mim neste exacto momento. $\mathrm{O}$ que torna privada uma experiência arreferente não é, portanto, ser eventualmente mais interna do que uma qualquer outra experiência. A ideia de uma experiência ser mais interna ou mais intrínseca que outra não faz qualquer sentido. Bem diversamente, o que torna privada a experiência de um quale, ou um seu par qualitativo, é não visar nenhum objecto ${ }^{25}$. Mais ainda: não visa um objecto porque não pode.

Com isto são suscitadas duas questões: i) porque é que os qualia, e os arreferentes em geral, não são intencionais (estando por isso limitados à perspectiva na primeira pessoa)?; ii) porque é necessário uma consciência intencional, aquela que visa objectos e tem-nos como seus referentes, para que possa surgir o ponto de vista da terceira pessoa?

No que se segue centraremos, por simplicidade, a discussão nos qualia, assumindo, pois, como legítima a generalização a todos os arreferentes.

\section{O que os qualia são}

Definimos qualia como estados mentais, de qualidade perceptiva, dotados de dois caracteres, 'experiência' e 'significação'. Podemos defini-los, alternativamente, como certa qualidade de experiências dotadas de significação mas desprovidas de referência intencional, ou ainda, como certa quali-

25 A respeito desta afirmação de que os qualia são privados por não serem objectais (e apesar de serem significativos), é muito interessante as observações de Luísa Couto Soares sobre a crítica de Wittgenstein às 'linguagens privadas' - "Nada nos impede de conciliar a crítica wittgensteiniana, lúcida e pertinente, com uma perspectiva da subjectividade do sentir na qual se reencontram a dimensão 'privada', enquanto sentir de um sujeito, com a dimensão 'pública' que lhe é conferida precisamente pelo seu carácter intencional. A ideia principal de Wittgenstein na sua argumentação conta a linguagem privada é precisamente corrigir o modo de entender as sensações como 'fenómenos internos', 'objectos de sentido interno', apresentando-no-los como 'estados de um organismo vivo'. O que é posto em causa é precisamente o estatuto 'objectal' das sensações, sentimentos, dores, etc.(...)" (Couto Soares, L.. "A dinâmica intencional da subjectividade", Análise, 21 (2000), Campo das Letras, Porto, p. 53) 
dade de experiências representativas não intencionais. Todas estas definições se equivalem. Por outro lado, julgo ser possível reconhecer um conjunto de outros características aos qualia (bem como aos seus pares qualitativos, isto é a todos os elementos da classe dos arreferentes).

1. Os qualia possuem um só aspecto experiencial. Quer isto dizer que aquando a experiência de um quale não é possível distinguir nela o que é propriamente experiência e o que é representação, embora esses dois caracteres sejam distintos e ambos estejam presentes. Um exemplo poderá elucidar esta unicidade aspectual: um dia perguntei à minha filha de 2 anos de que cor era a minha pasta de cabedal, ao que ela me respondeu que era cor-de-laranja, o que me levou, no primeiro instante, a pensar se a deveria corrigir já que a cor que eu esperava ver identificada seria o castanho. Em vez de a corrigir perguntei-me a mim mesmo por que razão eu esperava a resposta 'a mala é castanha', quando, bem vistas as coisas, a cor da mala era mais alaranjada do que castanha. Com certeza não era o caso de eu não saber distinguir cor de laranja de castanho - Com certeza domino a paleta das cores tão bem quanto a minha filha de dois anos! A resposta para esta situação algo paradoxal é simples: eu vi a mala como castanha, não me apercebendo que seria muito mais adequado vê-la como cor de laranja, porque a minha experiência qualitativa da cor da mala estava condicionada pelo conhecimento prévio que eu dispunha (mas a minha filha não) de que os objectos de cabedal em geral são acastanhados. Ora, tal conhecimento prévio não pode deixar de constituir parte da significação do quale que experienciei, pelo que esteve activa nessa minha experiência. No entanto, aquando essa experiência não distingui em momento algum um caracter 'significação' de um caracter 'experiência'. Bem diversamente, o que experienciei era já o produto de alguma forma de interacção entre esses dois caracteres. O castanho que vi era já informado, digamos assim, pela significação associada. E foi apenas esse que vi. Donde que, generalizando, os qualia possuam apenas um aspecto experiencial; generalizando ainda mais, os arreferentes são caracterizados por uma unicidade aspectual. Para finalizar, repeti a brincadeira com a minha mulher que respondeu, sem hesitações, 'a mala é castanha'.

2. Numa percepção, isto é, numa experiência em que um objecto é visado intencionalmente, os qualia não são propriedades do objecto da experiência, mas propriedades da experiência do objecto. Posso reconhecer num objecto de percepção, uma maçã por exemplo, propriedades como ser grande ou ser vermelha. Tais propriedades são reconhecidas no objecto experienciado, não na sua experiência. Mas, por outro lado, as propriedades do como é que é (o 'what it is like' de T. Nagel) o vermelho da maçã e mesmo a sua grandeza são propriedades reconhecidas na experiência do objecto, não no objecto propriamente dito. 
Há, contudo, autores, como Gilbert Harman, que defendem que estas últimas propriedades - os qualia - são ainda propriedades do objecto e não da sua experiência. Por exemplo, o ser vermelho da maçã é uma qualidade da maçã experienciada, não da experiência propriamente dita ${ }^{26}$. Michael Tye, por seu turno, afirma que não faz sentido falar de propriedades da experiência, pois, afirma ele, as suas experiências não serão com certeza coloridas não há experiências azuis, há tão-só experiências que representam um objecto como azul27.

Ora, M. Tye não se engana ao afirmar que o azul tem que ver com representações; engana-se, isso sim, em supor que os qualia não disponham desse caracter representativo. Quando se diz que os qualia são propriedades da experiência, em contraste com as propriedades do objecto de experiência, não está em causa o carácter representativo daquela experiência; está simplesmente em causa que se trate de uma representação intencional, isto é, dotada de um objecto. O equívoco de Tye reside apenas no facto de confundir qualia com experiências não representativas, i.é, com as sensações, tal como as definimos. E a estas, de facto, não faz sentido nenhum atribuir propriedades como ser azul ou vermelha, pois delas só há uma experiência indirecta, de não-reconhecimento. Este tipo de equívoco é, aliás, muito pronunciado, como salientarei na seguinte secção deste artigo, nos próprios qualiófilos.

O argumento de G. Harman, segundo o qual os qualiófilos fazem uma atribuição confusa de certas características do objecto de experiência à experiência propriamente dita desse objecto, aplica-se, exactamente como o de M. Tye, caso os qualia sejam entendidos como experiências desprovidas de significação. Mas não sendo esse o caso, é esse mesmo argumento que revela uma confusão entre propriedades representadas de forma não intencional na

26 "When you attend to a pain in your leg or to your experience of the redness of an apple, you are attending to a quality of an occurrence in your leg or a quality of the apple. Perhaps this quality is presented to you as an intrinsic quality of the occurrence in your leg or as an intrinsic quality of the surface of the apple. But it is not at all presented as an intrinsic quality of your experience." (Harman, G., 1990. "The Intrinsic Quality of Experience", in Block, Flanagan e Güzeldere, The Nature of Consciousness, p. 668)

27 "Standing on the beach in Santa Barbara a couple of summers ago on a bright, sunny day, I found myself transfixed by the intense blue of the Pacific Ocean. Was I not here delighting in the phenomenal aspects of my visual experience? And if I was, doesn't this show that there are visual qualia?

I am not convinced I experienced blue as a property of the ocean not as a property of my experience. My experience itself certainly wasn't blue. Rather it was an experience that represented the ocean as blue. What I was really delighting in, then, were specific aspects of the content of my experience. It was the content, not anything else, that was immediately accessible to my consciousness and that had aspects that were so pleasing" (Tye, M. 1992. "Visual qualia and visual content". In The Contents of Experience, edited by T. Crane. Cambridge: Cambridge University Press, p. 160 - citado de Martin, M. 1999."The Transparency of Experience" http://www.nyu.edu/gsas/dept/philo/courses/concepts/martin.html) 
experiência e propriedades representadas no objecto intencionalmente visado na experiência. ${ }^{28}$

Para clarificar este ponto 2, retomo o exemplo da minha mala de cabedal. Quando afirmo que ela é grande, pesada, e castanha mais não faço do que listar algumas propriedades do objecto mala. Quando procuro descrever o tom exacto do castanho da mala aquilo em que me basearei para levar a cabo com algum sucesso a descrição será o conjunto das outras experiências que me são reconhecíveis na experiência actual. Tomo, pois, duas atitudes diferentes consoante o meu interesse esteja nas propriedades do objecto experienciado ou nas propriedades da experiência do objecto. Quando presto atenção ao objecto intencional e às suas propriedades, a minha atitude é procurar reconhecer relações de pertença ou inerência entre um subjectum (o objecto) e acidentes (as suas propriedades objectivas). Digo então 'a minha mala é castanha', 'a minha mala é pesada', etc. Mas nessa circunstância não prestarei atenção às propriedades da experiência desse objecto. Quando é a estas que presto atenção, a minha atitude é procurar reconhecer relações de semelhança e dissemelhança entre o presente quale e outros qualia que participam da minha memória de experiências. Digo então 'o castanho da minha mala é como um cor de laranja sem brilho e algo escurecido', 'o peso da minha mala faz-me lembrar quando era pequeno e tinha de levar todos aqueles livros escolares para as aulas'. Na primeira atitude reconhecem-se relações de pertença, ao passo que na segunda atitude reconhecem-se relações comparativas. Naquelas, ao dizer-se ' $x \in A$ ' ou ' $x \notin A$ ' toma-se o objecto como um conjunto cujos elementos são propriedades; além disso, assume-se um compromisso com a consistência lógica. Nas relações comparativas reproduzem-se experiências mais públicas que contrastam ou se assemelham com a experiência actual; neste caso, o compromisso assumido é para com o efeito de verosimilhança $\mathrm{a}^{29}$.

Assim, quando se descreve um quale tal não poderá ser feito segundo o modo como se descreve um perceptum. Sob este modo de descrever percepta, regido por relações de pertença de propriedades a um objecto, todo o

28 Uma posição crítica relativamente aos argumentos de M. Tye e G. Harman, algo semelhante a esta, é exposta por Georges Rey - "Harman is presenting us with a wrong prediction (...). I think we can attend to 'intrinsic' properties of our experience, but without indulging in qualiaphilia and regarding those properties as properties of the representation." (Harman, G., 1997, Contemporary Philosophy of Mind, Blackwell, Oxford e Massachusetts, p. 302.)

29 Estabelecemos aqui um filiação forte da diferença entre a atitude própria à tematização de representações não intencionais e a atitude própria a representações intencionais (no caso da percepção, respectivamente qualia e percepta) na diferença aristotélica entre logos hermeneutikos e logos apofantikos. Na sequência desta filiação, a retórica e a poética, em contraste com o discurso sobre a verdade, são discursos que dão a experienciar propriedades comparativas de uma experiência, que reproduzem experiências para delas tirar um efeito experienciável (sob o compromisso da verosimilhança). 
quale é inefável. Mas daqui não se pode inferir, evidentemente, que os qualia sejam absolutamente inefáveis, pois, como se viu, é possível dar deles uma descrição em termos de relações comparativas com outras experiências, sem que umas pertençam a outras, sem que haja um $\mathrm{X}$ do qual se afirme um conteúdo a ele subordinado - em suma, em que, bem pelo contrário, as experiências se dizem inter pares. Se a teoria dos conjuntos pôde servir de modelo à silogística aristotélica é porque limita o discurso sobre a verdade a proposições, i.é, a enunciados que têm por estrutura a relação de pertença de um predicado a um sujeito. Ora, é justamente por esta razão que a descrição dos qualia não pode ter lugar a não ser por intermédio do discurso não proposicional, nem pode obedecer aos princípios de não-contradição e do terceiro excluído.

Indo um pouco mais longe, contra o design de uma imanência dotada de limites que são ou não transcendidos por propriedades, consoante se prediquem ou não dela - uma imanência reificada mas da qual não é possível qualquer experiência -, a descrição dos qualia, como o discurso não proposicional em geral, correlaciona experiências num mesmo plano, articula-as contingentemente num registo de permanência nesse mesmo plano. Produz, em síntese, uma autêntica imanência experiencial a que corresponde, arriscando um célebre conceito deleuziano, um plano de imanência.

3. Do ponto anterior extraem-se duas consequências da maior importância. A primeira é a de que, numa representação intencional, as propriedades da experiência não são directamente experienciadas. Uma tal consequência contradiz frontalmente a ideia, tão consensual quanto confusa, de que os qualia são experienciados directamente e, em todo o caso, experienciados mais directamente que os objectos de percepção. Por curioso que seja, verifica-se justamente o contrário. Eu só experiencio as características qualitativas de uma experiência perceptiva se converter a percepção num quale, isto é, se deixar de prestar atenção à objectidade intencionada para dirigir a minha atenção exclusivamente para a experiência dessa objectidade. E esta convertibilidade de percepções em qualia, bem como de todas as representações intencionais em não intencionais, pode ser tomada como um princípio central para uma teoria geral da experiência. Era esta a segunda consequência a retirar.

Estamos cientes do facto de que este princípio da convertibilidade das percepções em qualia (e, em geral, das representações intencionais em não intencionais) contradiz certas interpretações das observações resultantes de casos de Blindsight. No essencial, tais interpretações apontam no sentido de haver percepção de objectos sem que haja, de todo, qualia. Ou seja: afirma-se que algo é reconhecido sem que disso se tenha alguma forma de experiência. Os casos de Blindsight como, em geral, todos os casos denominados percepções inconscientes (unconscious perceptions) podem, contudo, ser 
interpretados diversamente. Por exemplo, Chalmers defende que "este tipo de caso não pode produzir evidência contra uma ligação entre a organização funcional e a experiência consciente". ${ }^{30}$ Evitar-se-á entrar aqui nesta discussão, tanto mais porque este exemplo patológico evidencia que numa percepção as propriedades do objecto experienciado não são também elas experienciadas. E nisto não há desacordo. O ponto de divergência reside apenas em saber se é possível experienciá-las, através de uma conversão de atitude que focalize o quale em detrimento do perceptum, ou se tal não é, de todo, possível.

Mais interessante é notar que Chalmers vai bem mais longe com o seu princípio da coerência entre awareness e consciousness do que nós com o que denominámos princípio da convertibilidade das percepções em qualia. Aquela tese de Chalmers, já referida na nossa secção 1, aponta para uma dupla convertibilidade (mas apenas em termos de atitude), pois, de acordo com ele, a todos os qualia correspondem formas de consciência-de (awareness). Ora, todos os exemplos de qualia dados até ao momento indicam claramente que neles não há nenhum caracter intencional, pelo que a tese de Chalmers é facilmente refutada. Não obstante, o interesse aqui está sobretudo em dar conta do modo como Chalmers interpreta, a nosso ver de forma equívoca, esses mesmos exemplos.

"Note-se que o princípio não é o de que sempre que temos uma experiência consciente estamos conscientes (aware) da experiência. Aqui o central é os juízo de primeira ordem, não os de segunda ordem. Quando experienciamos um livro, estamos conscientes (aware) do livro; quando experienciamos uma dor, estamos conscientes de algo doloroso (aware of something hurtful); quando experienciamos um pensamento, estamos conscientes do que quer que seja esse pensamento é acerca. (...)

O elo entre experiências e juízos de segunda ordem é muito mais indirecto: embora tenhamos a capacidade de relatar as nossas experiências, quase sempre relatamos os conteúdos da experiência, não a própria experiência. Só ocasionalmente recuamos e relatamos a nossa experiência do livro vermelho; usualmente apenas pensamos no livro. Enquanto os juízos de segunda ordem são infrequentes, os de primeira ordem são ubíquos." 31

$\mathrm{O}$ equívoco salta à vista pelo confronto entre os dois primeiros exemplos: se é verdade que 'quando experiencio um livro estou dele consciente' é porque, no caso, há um objecto da experiência (i.é, um objecto visado por uma consciência intencional); mas a afirmação 'quando experiencio uma dor tenho consciência de algo doloroso' não é, de todo, verdadeira, pois, no caso, pode não haver um objecto de experiência, pelo que resulta absurdo 
atribuir-lhe, com necessidade, uma consciência intencional. Um exemplo célebre serve-nos na perfeição: a experiência da angústia não dispõe de nenhum objecto a que se possa referir. E agora que exemplo de juízo de segunda ordem poderá Chalmers dar da experiência da angústia?

Em rigor, não é só uma mas duas as confusões a explicitar no raciocínio de Chalmers. A primeira está em ele não reconhecer senão experiências de objectos, falando em juízos de primeira ou de segunda ordem consoante se tematize o objecto ou a experiência, respectivamente. Não reconhece, pois, que as atitudes que tomemos face a uma experiência estão condicionadas pelo tipo de experiência em causa. Ou dito de outro modo: classifica tipos de experiência - consciousness e awareness - em função das atitudes e não o inverso ${ }^{32}$. Mas a impossibilidade de uma awareness da angústia refuta-o.

A segunda confusão, que redunda aliás em contradição, reside na assunção implícita de que só há efectivamente uma experiência - a experiência do objecto - e que a diferença se situa apenas no plano dos juízos que dela faço. Observe-se que Chalmers tematiza, na passagem acima transcrita, ou o vermelho do̊ livro ou o objecto livro sempre a partir da mesma experiência. Mas, nem a experiência se deixa analisar por um ou por outro lado sem passar a ser uma outra experiência (os nossos exemplos dos pontos anteriores bem o mostram), nem, bem vistas as coisas, é consistente supor que os juízos de segunda ordem não sejam, tal como os de primeira ordem, eles próprios experienciáveis.

4. Uma vez que os qualia são as propriedades da experiência e sendo que essas propriedades são de alguma maneira experienciáveis (se não como acederíamos aos qualia?), então é relevante levantar a questão de se saber se entre a experiência de um quale e o quale propriamente dito há alguma diferença. Segundo alguns autores a distinção não faz em si mesma qualquer sentido, pois, empregando um exemplo habitual, uma dor coincide com o sentir dessa dor. Dizem então, a respeito dos qualia, esse est percipi. O argumento até é bastante simples, no entanto, consiste numa generalização apressada. Com efeito, o exemplo da dor autoriza a falar em esse est percipi por nele se poder admitir que não há dor senão enquanto é sentida, por um lado, e não há sentir dor que não seja dor, por outro. Certos autores nem sequer aceitam esta equivalência, mas admitindo à partida que é verdadeira,

32 O mesmo tipo de equívoco parece estar presente na seguinte afirmação de Colin McGuinn - "what the experience is like is a function of what it is of, and what it is of is a function of what it is like". (McGuinn, C., 1988. "Consciousness and Content", in Block, Flanagan e Güzeldere, The Nature of Consciousness, p. 298) Isto não significa que McGuinn esteja equivocado quando, por outro lado, afirma que "(...)perceptual experiences are Janusfaced" (ibidem). É que esta última afirmação é pronunciada a respeito das experiências perceptivas, ao passo que aquela generaliza uma implicação de duplo sentido independentemente do tipo de experiência em causa. 
dela não se pode obter uma generalização que preserve a verdade, pois qualquer exemplo de representação intencional infirma-a. Nesses casos, pense-se numa qualquer percepção, por exemplo a de uma maçã vermelha, é evidente que há experiência e que ela tem propriedades a que chamamos qualia; simplesmente, essas propriedades não são tematizadas enquanto tais - o vermelho da maçã está lá, é o quale inerente à percepção, mas não é experienciado enquanto quale. Logo, em qualquer percepção, embora haja um esse dos qualia não há deles um percipi. Ele age sobre a percepção, mas passa em si mesmo desapercebido. Logo, esse non est percipi a respeito dos qualia.

Se temos o caso de nas representações não intencionais parecer, como no exemplo da dor, não haver distinção possível entre a dor e o seu sentir não é porque aí se verifique esse est percipi, mas tão-só pelo facto de os qualia estarem comprometidos com uma unicidade aspectual que não permite ao sujeito da experiência discernir o que é propriamente experiência do que é significação. Mas mesmo num exemplo como o de se sentir uma dor, que é a experiência de um quale, supor que esse est percipi (ou seja, que a dor e o seu sentir são o mesmo) conduziria ao absurdo todas aquelas familiares estratégias de comportamento que empregamos para evitar sentir uma dor que, no entanto, temos. Será que tentar distrair-me de uma dor de estômago é uma conduta absurda? E será que por evitar senti-la, procurando sentir outras coisas, ela deixa de existir? Não parece que assim seja em ambos os casos. Talvez por isso quando pensamos morder os dedos em situações de desespero, tal ajude um pouco a tolerar a situação, embora na verdade não resolva nada.

Esta redução ao absurdo não é tão simples quanto possa parecer, pois, apesar dela, ainda se pode sustentar que não há dor que não seja sentida e que não há sentir dor sem dor. Basta reconhecer que podemos sentir mais, ou menos, uma dor, e que as nossas estratégias face à dor vão todas no sentido de que a sintamos menos. Mas reconhecer isto é justamente reconhecer que entre uma e outra há uma clara diferença, ou seja, que é falso afirmar esse est percipi a respeito da dor.

5. Os qualia são produto de propriedades relacionais, mas não são eles próprios propriedades relacionais. Da exposição do ponto relativo à unicidade aspectual dos qualia retira-se facilmente esta conclusão. Nesse ponto mostrámos que um quale não discerne entre o caracter experiência e o caracter significação, nem que o primeiro caracter é informado pelo segundo, havendo pois entre eles uma relação, e que o quale é produto dessa relação ou interacção entre os dois caracteres.

Contudo, como vimos no ponto anterior, uma coisa é falar de qualia outra é falar de experiência de qualia. Quando eu pronuncio um juízo de percepção como 'a minha mala é castanha' tenho por base uma percepção dotada de um quale, i.é, uma experiência dotada de propriedades e que é 
experiência de um objecto. Quando me dou conta do facto de a minha mala não ser castanha mas alaranjada, tenho uma experiência do quale, i.é, uma experiência das propriedades da experiência do objecto. É precisamente neste segundo caso, em que além do esse tenho o percipi do quale, que é possível discernir as propriedades experienciais e suas relações e verificar que o quale experienciado é produto de propriedades relacionais. Ou seja, se chego a saber que os qualia são produto de propriedades relacionais é porque tenho deles uma experiência, na qual é possível reconhecer essas propriedades.

6. Os qualia envolvem pelo menos três ordens de condições: o estímulo, as condições de receptividade e as condições de reconhecimento. Quando se afirma que os qualia são produto de propriedades relacionais, importa identificar, tanto quanto for possível, os termos em relação nessas propriedades. No exemplo que se segue, determinaremos três desses termos, que designaremos por condições base das propriedades relacionais dos qualia.

Quando me encontro constipado e com o nariz obstruído, o tabaco sabe-me mal. Não me parece possível haver dúvidas quanto ao facto de o sabor se alterar nessa circunstância e que tal alteração do sabor não é devida ao tabaco que fumo, sendo antes induzida pelo estado do meu organismo, que não pode ser o mesmo por me encontrar constipado e com as vias respiratórias obstruídas.

Antes e depois de me constipar, o tabaco sabe-me, pois, diferentemente. Uma tal alteração é perfeitamente reconhecível. É, por conseguinte, uma experiência dotada de sentido; e trata-se obviamente de um quale. O problema que se levanta é outro. Consiste no facto de ninguém saber exactamente como me sabe o tabaco, esteja eu constipado ou não. É possível a um outro fumador reconhecer a situação de alteração do sabor pela recordação da sua própria experiência de alteração de sabor nessa circunstância. Mas como saber se o tabaco lhe sabe exactamente da mesma maneira que a mim? Mesmo alguém que não conheça o sabor do tabaco, pode compreender a minha situação por analogia com o sabor dos alimentos ou do café. De certo modo, não é pois difícil alguém compreender porque me sabe diferentemente o tabaco, embora sem que possa saber como me sabia dantes o tabaco e como me sabe quando me encontro constipado. O que se diz do sabor do tabaco, dir-se-á, mutatis mutandis, do modo privado como sinto o sol bater na cara, como vejo o sol pôr-se, etc. Os qualia, como já verificáramos, são privados e a sua experiência é também privada.

Este exemplo, como qualquer outro, demonstra que o sabor, apesar de experienciado de forma directa, depende necessariamente das condições de uma receptividade, que mais não é do que o estado do organismo do sujeito da experiência, e das condições de um reconhecimento, que não é mais do que a memória de sentido do sujeito (i.é a correlação de experiências que se 
imanentizam num só plano), e, portanto, não apenas do poder diferenciador do tabaco que fumo. Por isso, se denominámos qualia aquelas propriedades que se dizem da experiência e não do objecto da experiência, ou seja, as propriedades de uma representação não intencional, houve também que lhes reconhecer, a respeito da sua constituição, um carácter necessariamente relacional. Mais em particular, importa agora reconhecer pelo menos três factores em relação: o estímulo extra mens, as condições de receptividade desse estímulo numa experiência e, finalmente, as condições de reconhecimento dessa experiência numa significação. No nosso exemplo do fumador, ter-se-ão, pois, certos compostos moleculares que afectam as pupilas gustativas e desencadeiam um processo fisiológico bem complexo de recepção, tratamento e transmissão da informação. Este processo culmina na sensação ${ }^{33}$, que não é experienciável de forma directa, uma vez que dela não é possível nenhum reconhecimento (recorde-se que o exemplo de sensação que considerámos atrás era justamente caracterizada por uma experiência de não-reconhecimento). A experiência do quale resulta, finalmente, do reconhecimento subjectivo e espontâneo de um significação na experiência. É o momento em que direi "gosto deste tabaco!", "sinto mesmo a falta de nicotina!", "estou viciado nisto!", etc.

Assim, poder-se-á representar esquematicamente a constituição dos qualia como tendo três ordens distintas de condições:

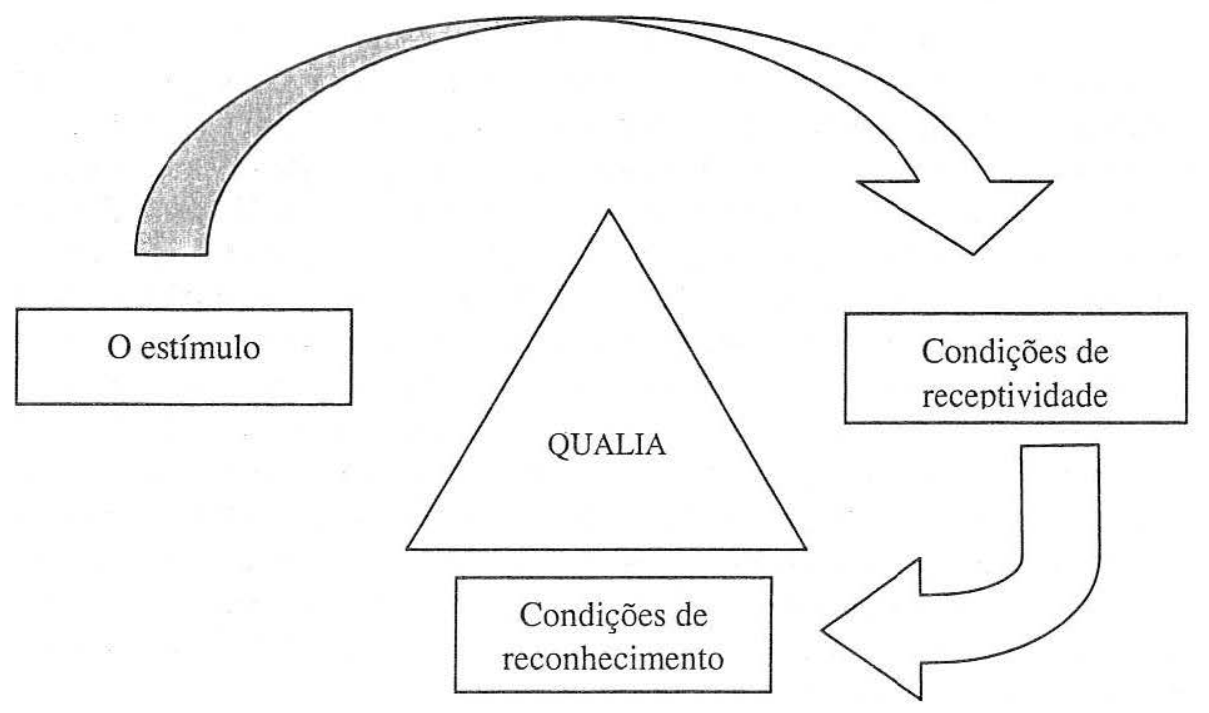

33 A explicação deste processo depende da possibilidade de dar uma resposta explicativa ao mind-body problem, tal como é habitualmente designado na literatura filosófica mais recente. Mas, observe-se, da carência de uma explicação para o processo não se infere de forma alguma a inexistência do mesmo. Em todo o caso, o presente artigo não se debruça sobre o mind-boddy problem. 
7. A identidade entre qualia só pode ser pensada como uma identidade entre o complexo relacional que está na sua base. Dito de outro modo, a pergunta 'é o quale o mesmo ou não?' é uma pergunta sem sentido a não ser que se converta essa questão numa outra 'é o complexo de condições que está na sua base o mesmo ou não?' Este ponto é fundamental no debate contra um dos mais reputados qualiófobos - Daniel C. Dennett.

Há uma certa maneira de argumentar que se caracteriza por rejeitar a existência de algo por se rejeitar a sua descrição objectiva, esquecendo que tal argumentação só é válida se se certificar primeiramente que a descrição é válida. Esse esquecimento pode dar lugar a toda a espécie de argumentos do homem de palha, que mais não são do que uma instância de falácias semânticas. Vem isto a propósito porque parece ser esse o caso na argumentação de Dennett no seu célebre Quining Qualia - segundo a sua descrição, os qualia seriam descritos como propriedades não relacionais, inefáveis, privadas e acedidas directamente. Como esta descrição não é aceitável por si mesma, então, conclui o autor, é verdade que os qualia não existem.

Com efeito, Daniel C. Dennett advoga a ideia de que se deve quinizar os qualia (i.é eliminá-los) através da refutação das propriedades de segunda ordem que supostamente os caracterizariam: não são propriedades intrínsecas, mas relacionais; não são introspectivamente objectiváveis, apenas o são pela perspectiva da terceira pessoa; e nem sequer são mais privadas e inefáveis do que quaisquer outras. Ned Block, numa linha em que o seguimos, nega que os qualia tenham alguma vez sido pensados como não sendo relacionais, não vendo pois no carácter relacional que Dennett lhes aponta qualquer razão para os 'quinizar'34. Aliás, tal como os definimos atrás, os qualia são produto de propriedades relacionais que têm por base pelo menos três ordens de condições. Um sucedâneo do argumento de Dennett, embora apresentado sob a forma de uma contradição, é empregue por Jennifer Church a propósito da P-consciência de Block:

"as propriedades fenoménicas de um estado têm de ser propriedades possuídas em virtude de alguma relação entre o estado e um sujeito, e, no entanto, não podem ser propriedades relacionais por ser suposto serem intrínsecas aos estados que as possuem. Se, por outro lado, se aceita que as propriedades fenoménicas são propriedades relacionais, parece plausível supor que as relações relevantes são alguma espécie de relações de acesso(...)."35

34 "Dennett, for example, has supposed in some of his writings that it is of the essence of qualia to be non-relational, incorrigible (too believe one has one is to have one) and to have no scientific nature. This is what you get when you let an opponent of qualia define the term." (Block, N., "Qualia" in Guttenplan, S. (editor), 1994. A Companion to the philosophy of mind, Blackwell, Oxford, p. 514)

35 Church, Jennifer, s/d. "Fallacies or Analyses?", in Block, Flanagan e Güzeldere, The Nature of Consciousness, p. 425. 
O erro está em pensar que o único caracter dos qualia é a experiência quando, como se viu, não é o caso que assim seja. Uma boa razão para este erro pode residir na confusão entre a unicidade aspectual dos qualia e uma suposta unicidade de caracter dos mesmos. Dessa presunção decorre uma confusão entre sensação e quale que deve ser posta a claro. Por um lado, os qualia são obviamente relacionais, e entre os termos da relação um deles é o background, o que implica acesso, mas de forma alguma intencionalidade ${ }^{36}$. Por outro lado, o que nos qualia é intrínseco é o caracter experiência, o qual não é menos intrínseco nas percepções. Mas não há contradição nenhuma, a respeito dos qualia, entre um acesso a significações, ser intrínseco e ser relacional. As sensações é que não são relacionais, nem dotadas de sentido, muito menos de acesso.

Talvez a simplificação dos tipos de experiência numa grelha com apenas duas entradas seja uma outra fonte destas confusões, talvez o próprio Ned Block tenha de algum modo contribuído para isso ao estipular uma dualidade forte entre P-consciência e A-consciência, sobrevalorizando naquela o caracter experiência em detrimento do caracter significado. Em todo o caso, há que chamar a atenção para o facto de que é também ele quem afirma que P-consciência e A-consciência, apesar de fortemente distinguidas, interagem.

Regressando a Dennett, um exemplo, entre os muitos que nos apresenta, é este - Dois homens experimentados no sabor do café trabalham para uma casa de cafés com a precisa função de preservarem as características do sabor original do café produzido nessa casa. Sucede que ambos os senhores, ao fim de seis anos, lamentam o facto do café agora já não lhes saber da mesma maneira e isto apesar de o café ter preservado as mesmas qualidades objectivas. De acordo com um deles, Mr. Chase, o café nem sequer sabe diferentemente; sucedeu, tão-somente, que os seus padrões de satisfação evoluíram com o passar dos anos de tal forma que esse sabor já não lhe agrada - na verdade, o mesmo sabor sabe-lhe agora mal. O que mudou, de acordo com Mr. Chase, foi apenas o seu gosto. Já Mr. Sanborn, o outro provador, julga, pelo contrário, que o sabor do café se alterou efectivamente e que lhe sabe mal não porque tenha mudado de gostos, mas precisamente por o sabor não ser o mesmo. Do seu ponto de vista, também o café é o mesmo, pelo que o que mudou foi a maneira como se constitui o sabor.

Face ao exemplo dos provadores de café, Dennett pergunta qual dos dois provadores tem razão, se é que não sucedeu com ambos um pouco das

36 A noção de um Background é retirada de John Searle, a que corresponde a seguinte definição: "O Background é um conjunto de capacidades mentais não representacionais [restringindo aqui o alcance de 'não representacionais' a 'não intencionais'] que permite que toda a representação tenha lugar "capacidades mentais não representacionais" (Searle, J., 1983. Intentionality. Intencionalidade, trad. Madalena Poole da Costa, Relógio d’Água, Lisboa, 1999, p. 185). 
duas coisas. Perguntando o mais simplesmente possível: É o quale o mesmo ou não? E disto conclui o autor que:

i) Não está ao alcance de nenhuma das duas personagens responder a esta questão de forma introspectiva, pelo acesso directo a essas experiências

ii) Sê-lo-á, bem pelo contrário, através de formas indirectas que não passam pela introspecção, formas ditas na terceira pessoa.

Aqui o problemático é que a própria questão "é o quale o mesmo?" revela imprecisão pois como se pode dizer tratar-se, ou não, do mesmo o que é relacional? Seria necessário que a relação e cada um dos termos da relação fossem os mesmos. Mais do que isso, seria necessário determinar quais e quantos são os termos relacionais e de que modo verificar a identidade, ou não, entre os termos em diferentes tempos. Ao não considerar os qualia produto de propriedades relacionais de um complexo de condições, como vimos no ponto anterior, Dennett limita-se a extrair uma conclusão a partir de uma premissa falsa, conclusão cujo valor de verdade permanece, pois, indeterminado. Não obstante, as afirmações i) e ii) são, a nosso ver, verdadeiras; simplesmente não servem, em nada, para quinizar os qualia, a não ser que o entendimento que temos destes coincidisse com a caracterização que deles dá Dennett. E não é esse o caso.

Mas, por outro lado, é preciso reconhecer que Dennett levanta um importante problema acerca da objectividade da experiência dos qualia.

8. Não sendo objectidades, os qualia podem ainda assim ser dotados de alguma objectividade. Se aprofundarmos os dois últimos exemplos, deparamo-nos com o facto de um fumador experimentado, como um provador de cafés, ou um escanção, etc., terem uma perspectiva na primeira pessoa bastante precisa das suas avaliações de gosto. Não só tematizam de algum modo as propriedades dos qualia que experimentam, como o fazem de tal forma que o resultado é dotado de alguma objectividade, no sentido mínimo que pelo menos saberão experienciar, com elevado grau de precisão, diferenças, até mesmo muito subtis, entre qualia. Afirmar o contrário equivale a afirmar que todo o escanção é inevitavelmente um falsário ou que é absurdo perder tempo a discutir as diferenças entre um Jack Daniel's e um bom Irish ou entre um Peterson e um Captain Black, etc. Não considerando tão desagradáveis suposições, interessaria detectar em que termos se constitui uma objectividade em torno dos qualia, note-se uma objectividade sem objectualidade. Procuraremos dar conta desta problemática, ainda que de forma muito resumida, no sexta e última secção do artigo. Em todo o caso, no que respeita ao presente ponto, temos por certo, nem que seja por recurso a reduções ao absurdo, que os qualia são dotados de algum tipo de objectividade. 


\section{O que os qualia não são}

É certo que qualiófobos como Dennett forçam um pouco a descrição dos qualia, mas não deixa de ser igualmente certo que reina muita confusão nas definições qualiófilas dos mesmos. E a este respeito interessa mostrar claramente que a nossa definição de quale não corresponde com exactidão à que tem sido consagrada na literatura sobre o assunto. Tome-se o caso de uma célebre definição de Sydney Shoemaker, em The Inverted Spectrum qualia são "as características qualitativas ou fenoménicas da experiência dos sentidos" 37 . De acordo com esta definição, quale é o aspecto qualitativo de uma dada experiência perceptiva, ao qual é preciso acrescentar, caso se trate efectivamente de uma percepção, um aspecto intencional. Correlativamente, dirá um qualiófilo, uma percepção possui um conteúdo intencional e um conteúdo qualitativo. Caso se trate de uma experiência mental desprovida de objecto intencional, por exemplo uma dor, então não se disporá de outro conteúdo senão o conteúdo qualitativo, nem de outro aspecto senão o experiencial.

Pondo de parte as noções de conteúdo, cujo compromisso podemos dispensar (até porque está contaminada pela ideia de uma relação de pertença do conteúdo ao continente), esta definição é equívoca por duas ordens de razão associadas:

1. Esta formulação tanto pode definir quale como sensação, dependendo isso do sentido que se atribua à expressão 'características qualitativas ou fenoménicas'.

2. como os exemplos geralmente apresentados de qualia são efectivamente qualia no sentido em que os definimos, então fica pouco claro, de acordo com a definição de Shoemaker, como distinguir neles o caracter 'experiência' do caracter 'significado'.

Isto leva a pensar que se deixou escapar na teorização dos qualia um ponto determinante e no qual muito temos insistido - o de que, para lá das representações intencionais e das experiências não representativas, existem representações não intencionais, precisamente aquelas que são distintivas dos qualia. E se assim é, então terão sido, algo ironicamente, os qualiófilos quem mais bem eliminou os qualia ao confundi-los com sensações.

O primeiro facto relevante a ter em conta aqui é que não é possível deixar de distinguir entre exemplos de experiências com sentido mas não referenciais, como a dor ou o vermelho de uma maçã vermelha, e exemplos de experiências completamente desprovidas de sentido, como aquelas em que não ocorre reconhecimento nenhum, seja objectal ou não. O segundo facto relevante é que só o primeiro tipo de exemplos tem sido apresentado na 
bibliografia sobre qualia como efectivos exemplos de qualia, o que indica muito claramente que tipo de experiência se tem tido em mente quando se utiliza tais exemplos. Destas duas premissas retira-se a conclusão de que os qualia têm um caracter próprio que os distingue das sensações. Esse caracter como afirmámos é a 'significação', pelo que os qualia se dizem experiências com sentido, ou representativas, mas não intencionais. Aliás, outra coisa não diz Ned Block numa interessante nota, quando chama a atenção para aspectos não experienciais (mas também não intencionais) da P-consciência:

"Eu disse que a P-consciência não é uma propriedade intencional e que diferenças intencionais podem produzir uma diferença P-consciente. Disse também que as propriedades $\mathrm{P}$-conscientes são frequentes vezes representacionais. A minha perspectiva é a de que, embora o conteúdo P-consciente não possa ser reduzido a ou identificado com conteúdo intencional, os conteúdos $\mathrm{P}$-conscientes têm frequentemente um aspecto intencional, e também que os conteúdos $\mathrm{P}$-conscientes muitas vezes representam de um modo não-intencional primitivo." 38

Se um quale significa como pode ele não visar nada? Ou reformulando: o que é significar sem significar algo que se diga então visado intencionalmente? O que pode ser uma representação não intencional?

Caso não se obtivesse uma resposta para estas questões, e fôssemos obrigados a recusar a ideia de uma representação não intencional, confrontar-nos-1́amos com um das seguintes situações: i) ou se remete os qualia para o plano das sensações; ii) ou se remete os qualia para o plano das representações intencionais; iii) ou, pura e simplesmente, se elimina os qualia, afirmando que entidades como essas parecem existir, mas não têm na verdade qualquer correspondente real. A primeira posição é defendida por todos aqueles que não reconhecem aos qualia nenhum poder representativo (entre os quais parecem estar alguns qualiófilos!). A segunda é defendida por aqueles que procuram mostrar que os qualia são dotados de intencionalidade (por não admitirem outras representações que não as intencionais), mas também todos aqueles que sustentam que não há sensações sem um conteúdo perceptual prévio, o que é uma posição ainda mais inflexível. Finalmente, a terceira tem tido, como acabamos de verificar, em Daniel C. Dennett o seu principal defensor. Mas, muito antes deste, já as Investigações Lógicas de Husserl parecem assumir uma posição eliminativista a respeito dos qualia.

Logo na primeira das suas Investigações Lógicas, o fenomenólogo distingue entre sentido, ou significado, e referência objectiva, como vimos atrás. Além disso, distingue, na Quinta Investigação e de forma muito clara, entre o objecto intencional visado (i.é, o referente objectivo) e o que designa

38 Block, N., idem, p. 408. 
"conteúdos verdadeiramente imanentes" da vivência intencional. De acordo com a nossa abordagem à temática dos qualia seríamos naturalmente levados a fazer corresponder a estes tais "conteúdos verdadeiramente imanentes". Contudo, Husserl, a este propósito, não só se refere a sensações - o que poderia não passar de uma diferença terminológica -, como parece não admitir a distinção entre o que designámos sensação e quale. É frequentemente citada a seguinte passagem:

"Se os chamados conteúdos imanentes são meramente intencionais, os pertencentes à consistência real das vivências intencionais, não são intencionais; integram o acto, tornam possível a intenção como pontos de apoio necessários, mas eles mesmos não são intencionais, não são os objectos representados no acto. Não vemos sensações de cor, mas coisas coloridas; não ouvimos sensações de som, mas a canção da cantora, etc." ${ }^{39}$

Estes elementos reais da vivência, que constituem o seu conteúdo propriamente imanente, não são por si mesmos intencionais. Por isso, não são referenciais. Mas na medida em que são a vivência propriamente dita, então há deles uma experiência vivencial que se caracteriza por ser não-temática. Ou seja: embora eu não tematize o vermelho da maçã que vejo defronte de mim, é certo que o vivo numa consciência não-temática. Este mesmo vermelho da maçã vermelha, como o som da canção que ouço e a que Husserl chama sensação, pelo menos corresponde a exemplos típicos de qualia. Note-se, porém, que a sensação tal como Husserl a entende não distingue entre a experiência representativa não intencional (os qualia como temos vindo a afirmar) da experiência muda, ou seja, as sensações. Esta indistinção poderá resultar, de uma posição de Husserl, de acordo com a qual, os qualia não existiriam. Aliás, são várias as indicações de Husserl nas Invest. Lógicas no sentido de que a implicação de significação por parte da referência objectiva ou da intencionalidade é uma implicação recíproca ${ }^{40}$. Mais do que isso, a própria recusa de um acesso às cores independentemente dos objectos que de facto possuem cor (e aos sons independentemente de um objecto de audição) aponta claramente nesse sentido. Finalmente, a afirmação de que há um primado da percepção sobre a sensação lê-se como a afirmação de que a experiência começa sempre por ser intencional (ou, o que é o mesmo, referencial) e que a sensação, bem como o quale, só pode ser tematizada abstractamente.

Assim, no âmbito das Investigações Lógicas há que retirar duas conclusões. Primeiramente, o que Husserl não parece admitir não é tanto que haja

39 Husserl, E., Logische Untersuchungen, V, §11.

40 "Na significação se constitui a referência ao objecto. Assim, pois, usar com sentido uma expressão é o mesmo que referir-se expressivamente ao objecto (representar o objecto). (...) A expressão por ter significação refere-se a um objecto.”(Husserl, E., idem, I, §15) 
experiências não intencionais, mas que haja significações não intencionais, isto é, representações não intencionais. Donde que excluindo os qualia, apenas restam as sensações como "conteúdos verdadeiramente imanentes" do acto intencional. Em segundo lugar, que tais experiências não intencionais, as ditas sensações, não têm lugar senão como "pontos de apoio necessários" de uma intenção. Ou seja: arriscando a generalização, para Husserl não há experiência sensorial independente de experiência perceptiva, e a sua tematização só é possível, num segundo momento, derivado, por abstracção da experiência perceptiva; quanto aos qualia, esses estão eliminados à partida, uma vez que entre representação e intencionalidade há uma implicação de duplo sentido.

\section{Experiência e comunicação}

Com esta última secção renovo a questão pendente de saber como é possível uma objectividade sem objectualidade e, subjacente a estas, uma significabilidade não intencional (ou arreferencial). O título da secção reproduz o título de um artigo de João Paisana, autor que, por vias bastante distintas das que estiveram em jogo nas páginas anteriores, afirma o seguinte:

"O enunciado de experiência é ante-predicativo e pré-objectivo, não é um enunciado de conhecimento. O seu sentido objectivo não se funda no conhecimento de um objecto. Por outras palavras, o seu sentido não pode ser determinado pelas suas condições de verdade, entendidas estas através da referência e da predicação." 41

Nesta passagem está condensado todo um conjunto de afirmações relevantes: i) há enunciados, ditos de experiência, que não são predicativos, i.é, que não têm por base a relação entre um sujeito e os predicados que lhe pertencem; ii) tais enunciados possuem sentido; iii) dispõem de um objectividade ou de um sentido objectivo; iv) as condições de tal objectividade não são condições de verdade e excluem, além da predicação, a noção de referência.

Ora, confrontando estas afirmações com a nossa afirmação de que há uma objectividade sem objectualidade (e uma significabilidade sem referência), salta à vista o paralelismo. Não só opusemos qualia e percepta (como consciência fenoménica e consciência intencional) através do critério de que existem significações desprovidas de referência, como indicámos que a atenção na experiência dos qualia (e, generalizando, em toda a consciência fenoménica) estabelece relações comparativas - de semelhança, dissemelhança experiencial - sob o constrangimento da verosimilhança, ao passo

41 Paisana, J., “Experiência e Comunicação”, Phainomenon, 1 (2000), Colibri, Lisboa, p. 79. 
que, na experiência dos percepta (e, generalizando, em toda a consciência intencional), a atenção estabelece relações de pertença - entre um substrato, dito sujeito de predicados, e as propriedades que lhe pertencem - sob o constrangimento da verdade.

Com este paralelismo por base, podemo-nos autorizar procurar encontrar pontos de apoio para a questão sobre como chega a haver uma significabilidade sem referência e uma objectividade sem objectualidade. Ou seja, procurar na investigação em torno das condições de objectividade dos enunciados de experiência a resposta adequada à nossa pergunta sobre a objectividade dos qualia em particular e a dos arreferentes em geral. E nesse novo território de investigação ganha pertinência a tematização de uma oposição, muito discutida no âmbito da filosofia hermenêutica, entre 'ente' e 'objecto', sendo que este resulta de uma modificação daquele pela qual é convertido num sujeito de predicados, cujas relações são de pertença e se verificam internas ao próprio objecto, cortando assim uma relação prévia (e constituinte de sentido objectivo) com a significabilidade e o mundo.

João Paisana reconhece a este plano pré-objectal e pré-teórico o privilégio das dimensões prática e poética da experiência, em detrimento de uma dimensão teórica, caracterizada em termos de predicação.

"a experiência não conduz directamente ao objecto; o que é encontrado de modo imediato na experiência deverá antes ser caracterizado como ente disponível ou como utensílio, isto é, ente intramundano. Deste modo, deveremos afirmar que a experiência não tem fundamentalmente, e muito menos exclusivamente, uma dimensão teórica. Uma dimensão de conhecimento. $\mathrm{O}$ sujeito da experiência não pode ser caracterizado essencialmente como sujeito cognitivo; ao inverso ele encontra o ente comportando-se de forma prática ou mesmo poética (artística)" 42

Aliás, o estabelecimento de pontes entre a problemática dos qualia, tal como tem sido tratada nas últimas décadas pela filosofia de expressão anglófona e esta via de investigação privilegiada na filosofia continental, muito em particular a partir da filosofia hermenêutica e da comunicação (desde o longínquo Dilthey) tem sido experimentado por nomes da filosofia norte-americana como Gilbert Harman e Piotr Boltuc ${ }^{43}$.

42 Paisana, J., "Discurso Científico e Poético na Filosofia de Aristóteles", Philosophica, 9 (1997), Colibri, Lisboa, p. 83.

43 Piotr Boltuc, a este propósito, afirma o seguinte: "The first person statements are based on an immediate experience (or on a hermeneutics) of qualia, and not on proof of any kind." E referindo-se a Harman acrescenta: "Harman adopts Dilthey's notion (he calls it Das Verstehen) which refers to the understanding non-reducible to the method of physical science in studying the mind. Das Verstehen refers to the irreducibly first-person experience necessary for understanding certain claims e.g. 'Pain!' As Harman put it, obviously following Nagel: "You can know everything objective there is to know about a person without knowing 
Não obstante, de acordo com a nossa exposição anterior, existem experiências de não-reconhecimento que são desprovidas do caracter significação, experiências mudas que nada significam e em nada se reportam ao sujeito da experiência. Tais experiências, que denominámos insignificantes, correspondem aos sense data e seus pares qualitativos. Por este facto, embora toda a experiência dotada de sentido (seja ela dotada de referência ou não) pressuponha um 'espaço de diálogo', pelo que tal experiência não se possa dizer muda, não é aceitável daqui concluir universalmente, como faz João Paisana, que "não tem fundamento falar de experiências privadas ou mudas" 44 . Aliás, se as experiências de não-reconhecimento são, a nosso ver, mudas e privadas, as experiências não-referenciais, embora não sejam mudas (pois significam algo e é possível ao sujeito que as experiencia dizer delas alguma coisa), não deixam, por isso, de ser privadas. Com efeito, a unicidade aspectual que caracteriza os arreferentes não permite que o caracter significação com a sua dimensão pública seja discernido do caracter experiência, do que se segue que a dimensão pública e dialogal da constituição do arreferente não limita a privacidade da sua experiência. Resumidamente: i) há experiências mudas, não há significações mudas; ii) há significações privadas, não há objectos privados.

Finalmente, temos então que se deve distinguir entre experiência intencional e experiência representativa, sendo que esta só exclui as sensações. Por seu turno, à consciência estrita de sensações podemos chamar experiência muda, uma vez que não dispõe de qualquer significado próprio, nada representa e dela, enfim, nada pode ser dito. Desta tripla distinção, resulta uma rejeição de que a intencionalidade seja uma propriedade essencial da consciência.

Já por outro lado, a célebre afirmação kantiana de que "o 'eu penso' deve poder acompanhar todas as minhas representações", dizendo respeito a toda a consciência representativa, respeita também aos qualia. No entanto, as sensações e toda a experiência muda em geral, embora sejam algo de que uma consciência é consciente, não são, de acordo com o ponto de vista que defendemos aqui, acompanhadas por uma auto-consciência, isto é, não são reportáveis a um 'Eu penso' kantiano. Significa isto que nem toda a experiência é acompanhada por uma experiência de si.

Concluindo:

i) há três caracteres da experiência - 'experiência', 'significação' e 'referência';

ii) a ocorrência de um, dois ou três desses caracteres é critério suficiente para discriminar, respectivamente, uma experiência muda, uma experiência representativa e uma experiência intencional; 
iii) a estas duas últimas há que associar, respectivamente, uma experiência de si e uma experiência objectal, por um lado, e uma perspectiva na primeira pessoa e outra na terceira pessoa, por outro.

iv) São os tipos de experiência representativa e intencional que determinam as perspectivas e não o inverso, conquanto seja sempre possível converter uma experiência intencional numa experiência representativa através da substituição da perspectiva na terceira pessoa pela da primeira pessoa (note-se que a conversa não é possível).

v) A perspectiva da terceira pessoa caracteriza propriedades de um objecto e fá-lo por meio de relações de pertença; a perspectiva na primeira pessoa caracteriza propriedades de uma experiência significativa e fá-lo por meio de relações comparativas (de semelhança, dissemelhança, contraste, etc.) entre experiências.

vi) Há experiências mudas, não há significações mudas; há significações privadas, não há objectos privados ${ }^{45}$.

\section{Abstract}

The discrimination between two points of view, or perspectives, in respect to consciousness, one on the first-person other on the third-person, deals with two concepts of consciousness - respectively, phenomenal consciousness and intentional consciousness (sections 1 and 2). I will accept, generally, this idea. However, I will argue that are not two, but three kinds of consciousness and typ of experience, making my point introducing the concept of different characters of experience (section 3). These characters are 'experience', 'signification' and 'reference/object', and when all of them occur I say that we have an intentional experience. If it lacks the last one, we have a meaningful experience, but without reference. Finally, if the only occurrence is 'experience', then the type of experience we live is a meaningless or mute experience. This 'taxonomy' allows classifying a perceptum as an intentional experience, a quale as a meaningful experience and a sense datum as a mute experience. On the other hand, it represents, as I claim, an approach much more clear, than those usually appears, to the question 'what qualia really are?' (sections 4 e 5). Moreover: it makes possible talk about objectivity of qualia, an objectivity without object (section 6).

45 Alguns dos pontos desenvolvidos neste artigo não o teriam sido sem um precioso conjunto de observações e precisões que devo a Luísa Couto Soares, João Paisana e Pedro Alves, que me obrigam, e reconhecidamente, a um agradecimento. 